\title{
Ensino de História e a invenção do comum: tensões identitárias em diferentes escalas na política curricular do Mercosul Educacional
}

\author{
History teaching and the invention of the common: \\ identity tensions in different scales in Educational \\ Mercosur's curriculum policy
}

\section{Enseñanza de Historia y la invención de lo común: tensiones de identidad en diferentes escalas en la política curricular del Mercosur Educacional}

\author{
Thalita Maria Cristina Rosa Oliveira* \\ Carmen Teresa Gabriel ${ }^{* *}$
}

\begin{abstract}
Resumo: Este artigo tem por objetivo analisar as estratégias políticas mobilizadas no processo de construção da proposta de reformulação curricular de História desenvolvida no âmbito do Setor Educacional do Mercosul (SEM). Trata-se de compreender o processo de produção e fixação de um sentido de identidade regional supranacional em meio aos processos de identificação que abarcam escalas territoriais diferenciadas. Como acervo empírico, utilizamos, para a análise, documentos curriculares relacionados à área, tendo como aporte teórico-metodológico as contribuições das teorizações do discurso filiadas às perspectivas antiessencialistas. O estudo evidencia as lógicas de articulação entre diferentes demandas pela efetivação de um projeto político de integração econômica entre os países membros do MERCOSUL, legitimado pela tentativa de hegemonização de um sentido de "identidade regional latino-americana".

Palavras-chave: Currículo de História. Identidade regional latino-americana. Teoria do discurso.
\end{abstract}

Abstract: This article aim is to analyze the political strategies of the construction of
a proposal for the reformulation of History curriculum developed in the scope of
the Mercosur's Educational Sector. It searches to understand the creation and settling
of a supranational regional identity among the processes of identification that span
different territorial scales. As empirical collection, we used, for this analysis, curriculum

* Mestre em Educação pela Universidade Federal do Rio de Janeiro. Professora de História da rede pública estadual e municipal do Rio de Janeiro. E-mail: <thalita_mc@yahoo.com.br>

** Docenteda FaculdadedeEducaçãoda UniversidadeFederal do Rio deJaneiro.E-mail:<carmenteresagabriel@ gmail.com> 
documents related to the area, having as methodological and theoretical basis contributions on the theory of the discourse affiliated to anti-essentialist perspectives. The study highlights articulations between different claims for the effectuation of a political project of economic integration between Mercorsur countries, legitimated by an attempt to create a hegemonic "regional Latin-American identity".

Keywords: History curriculum. Regional Latin-American identity. Theory of the Discourse.

Resumen: En este artículo se pretende analizar las estrategias políticas de la construcción de una propuesta para la reformulación del plan de estudios de Historia en el ámbito del Sector Educativo del Mercosur. Se busca entender la creación y el asentamiento de una identidad regional supranacional entre los procesos de identificación que abarcan diferentes escalas territoriales. Como recopilación empírica, hemos utilizado, para este análisis, documentos curriculares relacionados con la área, teniendo como base las contribuciones teóricas y metodológicas de la teoría del discurso afiliada a perspectivas anti-esencialistas. El estudio pone de relieve las articulaciones entre las diferentes demandas de efectuación de un proyecto político por la integración económica entre los países del Mercorsur, legitimados mediante un intento de crear una "identidad regional latinoamericana" hegemónica.

Palabras clave: Plan de estudios de Historia. Identidad regional latinoamericana. Teoría del Discurso.

Atualmente é preciso considerar essa tradição no ensino de História, mas é necessário, simultaneamente, repensar sobre o que se entende por identidade e qual a sua relevância para a sociedade brasileira contemporânea. (BRASIL, 1998, p. 34, grifo nosso).

O trecho acima foi extraído dos Parâmetros Curriculares Nacionais de História para o Ensino Fundamental no Brasil, documento que, embora publicado no final dos anos 1990, até hoje produz efeitos na política curricular dessa disciplina escolar. Entre esses efeitos, destacam-se os que incidem diretamente na função político-ideológica atribuída ao currículo da disciplina ao longo de sua trajetória e assumida como tradição tal como formulada na citação que serve de epígrafe a este texto.

Afinal, como aponta Goodson (1995, p. 27), o currículo percebido como uma construção sócio-histórica é um "exemplo perfeito de invenção de tradição”. Em se tratando de História, a invenção está diretamente relacionada à produção e à sustentação de uma memória nacional, um dos principais eixos articuladores dos objetivos do ensino de História.

Desde o século XIX - quando a formação do espírito patriótico toma força e também serve como estratégia de ação de projetos político-ideológicos dos Estados nacionais em processo de consolidação -, o ensino de História 
tem sido um dispositivo educativo potente na formação de um sentimento de nacionalidade, atrelado principalmente à criação de laços de pertencimento e de lealdade ao espaço territorial de um país por meio da mobilização de processos de identificação às tradições culturais comuns igualmente inventadas (HOBSBAWM; RANGER, 1984).

Atualmente, as discussões em torno do ensino de História e sua relação com a produção da identidade nacional estão sendo afetadas pelo impacto do processo de globalização em curso e pelos indicativos políticos e econômicos da crise dos Estados-nação, em favorecimento da transnacionalização da economia, associada às privatizações das empresas estatais por grupos internacionais, em que o nacionalismo tende a perder importância no atendimento aos interesses econômicos.

Da mesma forma, o debate teórico em torno do conceito de identidade, bem como as discussões sobre identidade nacional, são revisitados, traduzindo os ares de nossos "tempos-pós" (GABRIEL, 2008) marcados pela eclosão de manifestações identitárias que mobilizam várias formas de pertencimento, como as de gênero, de etnia, de religião, de região, de orientação sexual, e que lutam pelo seu reconhecimento no cenário político contemporâneo. Não é por acaso que o sentido unívoco e engessado de identidade nacional, até então hegemônico, passa a ser problematizado e contestado (HALL, 2005).

A incorporação, por diferentes campos das ciências sociais, das contribuições dos Estudos Culturais (HALL, 1997, 2000, 2005; BHABHA, 1998) autoriza, aliás, estender a observação acima sobre a problematização de um sentido de identidade nacional para qualquer outra marca identitária. O que está em jogo é a definição deste termo, antes mesmo de ser associado a um ou outro adjetivo, como, por exemplo, "nacional", "regional" "cultural". Trata-se do desafio político e epistemológico de continuar pensando esse conceito em uma pauta antiessencialista e pós-fundacional ${ }^{1}$ (MARCHART, 2009), isto é, no âmbito de um quadro de significação em que o conceito de identidade seja percebido como relacional, contingencial e provisório. Isso significa não apenas reconhecermos a pluralidade de identidades, mas também assumirmos a dinamicidade, a historicidade e a fluidez dos processos de identificação em meio a sistemas de diferenças nos quais nos constituímos como sujeitos políticos.

Desse modo, o exercício intelectual de repensar o lugar do ensino de História, a partir das novas orientações teóricas pautadas nesse processo de

\footnotetext{
${ }^{1}$ Marchart (2009) nomeia de pós-fundacional as perspectivas de ver que interrogam e problematizam de forma constante as figuras metafísicas fundacionais, tais como a totalidade, a universalidade, a essência, que sustentam as explicações dos fenômenos sociais. Para esse autor, o pós-fundacionalismo não é sinônimo de antifundacionalismo, uma vez que aquele não procura apagar por completo essas figuras do fundamento, mas, sim, enfraquecer seu status ontológico.
} 
mudança centrado na questão da produção da identidade/diferença, é uma tarefa política e epistemológica que se coloca para os pesquisadores da área. Afinal, em quais processos de identificação o currículo de História deveria investir e/ou continuar investindo frente às "demandas de diferença" que interpelam a escola na atualidade?

Nessa mesma ordem de reflexão, esse tipo de questionamento e de desafio também se impõe para o ensino de História quando se trata de repensar os processos de identificação que mobilizam lealdades territoriais de diferentes escalas, como é o caso do Mercosul.

Como trabalhar, nos currículos de História dos países membros, as respectivas narrativas nacionais com as quais os alunos possam se identificar quando, para além das "demandas de diferença", internas a cada país, estão em jogo igualmente processos de identificação que ultrapassam o espaço nacional na intenção de se construir uma identidade regional supranacional, tal como proposto pelo Mercosul Educacional?

Uma primeira leitura do documento Para uma História e Geografia da Integração Regional, publicado em 1995, um dos primeiros textos oficiais que apresentam uma discussão sobre os fatores centrais para a reformulação curricular, não deixa dúvidas sobre o lugar relevante atribuído à História, ao considerar o ensino desta disciplina como

[...] possibilidade para a consolidação das raízes históricas dos países, que serão a base para uma real integraşão. Conhecer e compreender a História e Geografia de povos que se unem num Mercado Comum representa um esforço muito importante na busca de opções que levem a uma convivência marcada pela tolerância e pela compreensão. (PARAGUAY, 1995 apud CUNHA, 1995, p. 11, grifo nosso).

Nosso objetivo neste texto é justamente analisar as estratégias discursivas mobilizadas nos processos de identificação que fixam sentidos de "identidade nacional" e "identidade regional" nas propostas de reformulações curriculares desenvolvidas no âmbito do Setor Educacional do Mercosul (SEM).

Para tal, operamos com o sentido de currículo formulado pelas abordagens discursivas presentes no campo que combatem as perspectivas essencialistas nas leituras de mundo oferecendo subsídios teóricos para defini-lo como "espaço híbrido de enunciação", "espaço-tempo de fronteiras produtor de identidade e diferença” (MACEDO, 2004, 2006). Nessa perspectiva, não estamos

\footnotetext{
${ }^{2}$ Temos utilizado a expressão "demandas de diferença” para nomear o conjunto de reivindicações formuladas no seio de movimentos sociais presentes no cenário político contemporâneo e que estão relacionadas à questão de pertencimentos identitários. Junto com as demandas históricas de igualdade, as demandas de diferença que emergem no debate político mais recentemente configuram as demandas de direito que interpelam as escolas da educação básica em nossa atualidade.
} 
falando de currículo em geral ou de currículo de História, em particular, como algo coisificado. Nem listagem de conteúdos, nem tampouco um artefato cultural. No tipo de abordagem discursiva aqui privilegiado, o sentido de currículo é fixado como espaço-tempo poroso, permeado de diferentes fluxos de sentidos de conhecimento, professor, aluno, História ensinada. Isso não significa que esta seja a definição mais correta ou verdadeira, ou que esse sentido estivesse pré-fixado à espera das perspectivas pós-fundacionais para revelá-lo. Nada seria mais contrário à abordagem discursiva aqui defendida. Ao fixar, dessa forma, em meio a outras definições disponíveis, estamos intencionalmente demarcando uma fronteira do que "é" e do que "não é" currículo, operando assim com as teorizações de discurso para as quais os objetos são relacionais.

Importa, assim, olhar para os documentos curriculares da área de História que servem de empiria para esta análise como um terreno de disputa entre diferentes processos de identificação que fazem apelo a "passados comuns", em função das demandas de nosso presente em meio às lutas de significação pela definição do que "é" ou do que "não é" identidade nacional e/ou regional.

Esse tipo de posicionamento traduz uma outra forma de politizar o debate no campo do currículo, apostando na possibilidade de outra leitura política do cultural, abrindo, desse modo, pistas para se repensar a interface currículo e cultura em tempos do que alguns autores vêm chamando de uma verdadeira "virada cultural". Afinal, como afirma Hall (1997, p. 14), "a cultura não é nada mais do que a soma de diferentes sistemas de classificação e diferentes formações discursivas aos quais a língua recorre a fim de dar significado às coisas".

É, pois, nessa perspectiva que estudos curriculares mais recentes argumentam na direção de uma política da diferença oferecendo subsídios teóricos para a reflexão sobre as articulações entre o cultural, o econômico e o político mobilizadas nas políticas de currículo, como a que é objeto de análise neste texto. A noção de articulação é aqui entendida como um movimento de hibridação ${ }^{3}$ que revela o entrecruzamento de fronteiras entre diferentes formações discursivas no âmbito das quais são formuladas as demandas que interpelam as diferentes instituições sociais em nosso presente.

\footnotetext{
${ }^{3}$ Este termo emerge nas formulações de Nestor García Canclini, como o intuito de compreender como diferentes processos de significação se articulam em contextos discursivos específicos. Este autor, na introdução à edição de 2001 da obra Culturas híbridas, esclarece alguns aspectos acerca do conceito: "Entendo por hibridação processos socioculturais nos quais estruturas ou práticas discretas, que existiam de forma separada, se combinam para gerar novas estruturas, objetos e práticas. Cabe esclarecer que as estruturas chamadas discretas foram resultados de hibridações, razão pela qual não podem ser consideradas fontes puras. [...] A hibridação não é sinônimo de fusão sem contradições, mas, sim, pode ajudar a dar conta de formas particulares de conflitos geradas na interculturalidade recente" (GARCÍA CANCLINI, 2003, pp. XVIII e XIX).
} 
Para fins da análise aqui proposta, importa igualmente levar em conta as contribuições do campo do currículo que incidem sobre a questão do conhecimento escolar, ou mais particularmente sobre a interface conhecimento/ cultura/poder. Nosso propósito consiste em perceber como esta interface é significada nos textos curriculares da área de História produzidos no âmbito do Setor Educacional do Mercosul (SEM), cuja intencionalidade explicitada, como já anteriormente mencionada, consiste em contribuir para a construção de uma identidade regional envolvendo diferentes países, o que significa extrapolar o espaço nacional. Que passados são recontextualizados nesses textos para alcançar tal objetivo? Essa questão torna-se ainda mais desafiadora ao concordamos com Gabriel (2005, p. 45) quando afirma

[...] desenvolver o espírito patriótico, o civismo, construir a memória nacional ou recuperar memórias esquecidas são objetivos que permeiam e tensionam o ensino de História a despeito das concepções históricas sobre as quais se baseiam. Apesar de o Estado nacional não poder ser mais considerado como o principal e único fator dos destinos dos povos e de ser necessário reconhecer o enfraquecimento dos laços de lealdade a uma cultura nacional - vista como homogênea e estável -, a "possibilidade de um ensino de História totalmente liberado do esquema nacional" (Colliot-Thélène. 1997, p. 51) parece-me dificilmente concebível (e muito menos desejável).

Organizamos este texto em duas seções. $\mathrm{Na}$ primeira, reconhecendo as imbricações entre currículo e relações assimétricas de poder, e em diálogo com autores que contribuem para a sustentação da abordagem discursiva anteriormente mencionada, interessa-nos evidenciar, nos documentos do Mercosul, a intencionalidade da construção de uma identidade regional de escala supranacional, bem como o lugar de destaque atribuído ao ensino de História nesse processo. Na segunda parte, nossa intenção é analisar, nos textos curriculares, as estratégias ou lógicas de articulação mobilizadas nos processos de identificação de escalas territoriais diferenciadas, procurando compreender como as mesmas acontecem na etapa inicial da construção de uma política curricular de História em meio às disputas pelo controle de um projeto político educacional para a América Latina, como é o caso da criação do SEM. 


\section{Ensino de História no Setor Educacional do MERCOSUL (SEM): um projeto político em construção}

Tendo em vista as particularidades do contexto discursivo onde emerge o projeto político envolvendo o ensino de História no SEM, em que medida podemos nomear a política do MERCOSUL como também uma política curricular e como tal produtora de identidade/diferença? Para respondermos a essa pergunta, optamos não somente por procurar indícios nos documentos oficiais que legitimam tal política, mas igualmente buscar interlocução com autores que oferecem ferramentas de análise para pensar a dimensão política no campo do currículo em consonância com as abordagens discursivas, não essencialistas, privilegiadas neste estudo.

A hibridização teórica aqui defendida (MARCHART 2009; LACLAU; MOUFFE, 2004; LACLAU, 1996, 2005; BALL, 1990, 1993, 2001, 2004) e da qual lançaremos mão ao longo de nossa argumentação produz efeitos na leitura do social que nos parecem importantes destacar de forma sintética, tendo em vista o foco de nossa análise: (i) o entendimento do social como uma configuração significativa; (ii) o reconhecimento da impossibilidade de uma significação única; (iii) o entendimento de identidade como resultante de articulações discursivas; (iv) o entendimento de política curricular como resultante de uma multiplicidade de sentidos que circulam em diferentes contextos produtores de políticas; (v) o entendimento de luta política pela hegemonia como estratégias de universalização, homogeneização de um sentido particular, assumindo o papel de representar os diferentes sentidos em um contexto discursivo específico.

Uma primeira pista para responder a questão acima colocada pode ser encontrada nos estudos de autores brasileiros como Mainardes (2006) e Lopes (2004, 2006), que ao incorporarem em suas análises sobre políticas de educacionais as contribuições de Stephen Ball (1993, 1994, 2001) apontam quanto o currículo vem assumindo uma centralidade nos assuntos que dizem respeito às políticas educacionais na atualidade. Como afirma Lopes (2004, p. 110): “as mudanças nas políticas curriculares [...] têm maior destaque a ponto de serem analisadas como se fossem em si a reforma educacional".

As pesquisas sobre políticas curriculares vêm ganhando força, em grande parte, como resultado das reformas curriculares desenvolvidas em vários países entre os anos 1980 e 1990, no âmbito do processo de globalização. Isso tende a demonstrar que, hoje em dia, as mudanças curriculares ocupam um papel de destaque na ação do poder central de um país, funcionando como uma das estratégias políticas que contribuem para a sustentação de um projeto de sociedade que se quer hegemônico. É, pois, nesse movimento mais amplo que se insere a proposta curricular que começa a ser esboçada a partir da segunda metade dos anos 
1990 no âmbito do MERCOSUL. Interessante sublinhar, no entanto, que não se trata de uma reforma curricular no sentido de propor mudanças a algo já existente, hegemonicamente estabilizado, que poderia ser nomeado de "currículo de História latino-americana". A proposta curricular, objeto de discussão no MERCOSUL, traduz condensações e deslocamentos de tradições inventadas no que concerne aos processos de seleção de conhecimento em meio à tradição disciplinar dessa área de conhecimento, como procuraremos evidenciar na segunda seção.

A particularidade do SEM nos obriga a repensar o lugar da proposta curricular de História na ação de um poder que ultrapassa as fronteiras nacionais. Em que medida essa proposta tende a sustentar o projeto supranacional que ela representa? $\mathrm{Ou}$, ainda, como as políticas curriculares formuladas nesse contexto participam do jogo político que define e hegemoniza, por exemplo, um sentido de sociedade latino-americana? Não se trata aqui de avaliar a pertinência, nem a eficiência de uma política, mas de procurar compreender sua dinâmica na contingência do contexto no qual ela se desenvolve.

Uma outra relevante contribuição dos estudos sobre políticas curriculares (BALL, 1993, 1994, 2001; MAINARDES, 2006; LOPES, 2004, 2006) diz respeito ao entendimento da ação do Estado no processo de reforma curricular. A compreensão do papel desempenhado pelo currículo nas formulações dos projetos políticos elaborados no âmbito do poder central ganha sustentação teórica quando articulada às reflexões sobre o próprio entendimento de política. Nesta perspectiva, não caberia mais operar com a concepção do Estado como o único enunciador nos discursos produtores de políticas de currículo.

A proposta metodológica do ciclo contínuo de políticas, formulada por Stephen Ball, permite justamente problematizar a análise estadocêntrica ainda muito presente nos estudos de políticas educacionais. Para esse autor, a ação política envolve uma variedade de contextos em que são produzidas "escritas" e "leituras" dos textos políticos, agora percebidos como produtos dinâmicos e contingentes de processos políticos mais amplos. Ao enunciar a ideia de circularidade de sentidos nos textos de política, Ball (1993) abre a possibilidade teórica de pensarmos as políticas curriculares de forma a estar atento às relações de poder nelas incorporadas e, simultaneamente, questionarmos visões engessadas e hierarquizadas que tendem a congelar de forma dicotômica estrutura e ação.

Em diálogo com Stephen Ball, entendemos que os documentos analisados na segunda seção deste trabalho podem oferecer elementos importantes para a compreensão da trajetória de construção das políticas em meio a diferentes contextos discursivos. No caso deste estudo, trata-se principalmente do 
contexto de influência ${ }^{4}$, já que, talvez, por seu caráter embrionário ${ }^{5}$, a proposta curricular para a área de História do Mercosul Educacional não teria, ainda, sido objeto de outras interpretações pelo poder central de cada um dos países ${ }^{6}$ membros, nem tampouco pelos seus respectivos contextos institucionais de formação aos quais essa proposta está endereçada.

Desse modo, e para fins desta análise, entendemos os textos/discursos analisados como traçados das políticas curriculares em processo de formulação em meio às disputas travadas no contexto discursivo do MERCOSUL que o define como bloco econômico regional no ambiente da globalização.

Com efeito, a assinatura do Tratado de Assunção, em março de 1991, que selou o acordo de livre comércio entre Argentina, Brasil, Paraguai e Uruguai, formando o Mercado Comum do Sul (MERCOSUL), não definiu nenhuma prerrogativa em relação à questão educacional. Tratou-se da criação de um bloco econômico cuja existência dependia da articulação de demandas e interesses oriundos desses diferentes países. É possível perceber já neste documento a expectativa de alcançar uma integração regional, como deixa entrever a passagem: "o presente Tratado deve ser considerado como um novo avanço no esforço tendente ao desenvolvimento progressivo da integração da América Latina" (TRATADO DE ASSUNÇÃO, 1991, p. 1, grifo nosso).

A pretensão de uma integração da América Latina (integração regional) torna-se, assim, o mote que justificará a pertinência de outros aspectos, além

\footnotetext{
${ }^{4}$ Entre os contextos em questão, Ball destaca e desenvolve, com mais profundidade, três. O primeiro é chamado de contexto de influência (referente às definições políticas e à construção dos discursos políticos que abarcam as discussões sobre as finalidades sociais da educação, sendo alguns dos atuantes as agências multilaterais, as redes sociais que permeiam os partidos políticos e as políticas educacionais de outros países, que são dadas como referências a determinado país). O segundo - contexto de produção dos textos das definições políticas - está relacionado à própria elaboração dos textos curriculares pelo poder central, mantendo assim uma articulação mais direta com o primeiro contexto. E, por fim, o contexto da prática, em que as políticas curriculares são recriadas e reinterpretadas.

${ }^{5}$ No que se refere mais particularmente ao currículo de História, identificamos, como resultado dos debates atuais entre os responsáveis pela sua produção, muito mais um esboço ou esquematização de como pensar a elaboração de um currículo oficial de perspectiva regional. Consequentemente, a política curricular de História no âmbito do Mercosul Educacional encontra-se em processo de produção, sendo um dado que não pode ser negligenciado na análise da referida política curricular.

${ }^{6}$ Não é nosso propósito de investigação, mas cabe destacar que nos Parâmetros Curriculares Nacionais de História não há qualquer discussão ou apontamento da questão do ensino de História no contexto do MERCOSUL, o que de certa forma causa, no mínimo, estranhamento. Naquele momento, a presidência do país estava sob o comando de Fernando Henrique Cardoso, e o então Ministro da Educação e Desporto de seu governo, Paulo Renato de Souza, afirmou a necessidade de se construir uma ação cooperativa entre os países do MERCOSUL no que tange aos assuntos educacionais visando à formação "não só de uma nova entidade econômica, mas também de uma nova entidade cultural, dotada de visão regional, que concilie as diferenças e que estimule as concordâncias" (SOUZA, 1995 apud PERES, 2002, p. 143). Além disso, essa proposta curricular nacional (PCN de História) pensada e aprovada no contexto da criação do Setor Educacional do MERCOSUL trazia a própria questão identitária como um dos pontos centrais de sua estruturação.
} 
do econômico, no âmbito do MERCOSUL. Desse modo, já ao final de 1991, ocorreu uma reunião entre os Ministros de Educação dos países signatários, formalizando um Protocolo de Intenções, ocasião em que a Educação é anunciada como um dos aspectos importantes para integração regional (POLETO, 1995).

É esse Protocolo de Intenções que dá origem ao Mercosul Educacional, chamado oficialmente de Setor Educacional do Mercosul (SEM). O objetivo central do SEM é desenvolver políticas na área da educação que assegurem o processo de integração regional. A Reunião de Ministros é instância máxima do SEM (de nível político), assessorada pelo Comitê Coordenador Regional (CCR) (de nível técnico), apresentando como integrantes especialistas dos Ministérios da Educação dos países membros, na definição de políticas e estratégias comuns para a educação no campo de atuação do SEM. Subordinada ao CCR, a Comissão Regional Coordenadora de Educação Básica (CRC-EB) inclui entre suas competências um Grupo de Trabalho de Ensino de História e Geografia, indicando a importância atribuída a essas áreas de ensino escolar no processo de construção de identidades sociais.

De acordo com as decisões apresentadas na Ata da III Reunião de Ministros da Educação dos países signatários do MERCOSUL, realizada em Brasília no dia 27 de novembro de 1992, o Plano Trienal ${ }^{7}$ (aprovado em junho de 1992), primeiro plano educacional do setor, institui “o papel estratégico desempenhado pela educação no processo de integração, para atingir o desenvolvimento econômico, social, científico-tecnológico e cultural da região" (BRASIL, 1992, p. 1, tradução nossa). Em relação ao papel do ensino de História especificamente, destaca a necessidade de "promover, através dos Sistemas Educacionais, a inclusão de conteúdos vinculados ao atual processo de integração do MERCOSUL nos currículos correspondentes, particularmente nas áreas de História, Geografia, Língua e Literatura" (BRASIL, 1992, p. 3, 3º, grifo nosso, tradução nossa).

Desde sua primeira versão, o Plano Trienal - que tinha por objetivo estabelecer os princípios do projeto educacional no âmbito do MERCOSUL atrelados a seus interesses enquanto bloco econômico-regional - remete também à constituição de uma política curricular, na busca de definir instrumentos que possam dar conta de uma regulação daquilo que deve ser ensinado em contextos escolares.

\footnotetext{
${ }^{7}$ O referido Plano Trienal foi prorrogado por igual período até 1997, e, entre os anos de 1998 e 2000, foi formalizado um segundo Plano Trienal, com a renovação de ações na definição de programas e projetos de perspectiva regional. Após o término de vigência do Plano Trienal, em 2000, outros planos passaram a orientar as ações do SEM: Plano Estratégico 2001-2005 e, posteriormente, o Plano do Setor Educacional do MERCOSUL 2006-2010.
} 
Nota-se, assim, que o ensino de História ${ }^{8}$, no âmbito do Mercosul Educacional, passa a ser encarado como um dos elementos-chave para a promoção da integração regional, destinando-se a proporcionar a construção de uma identidade regional. A proposta de reformulação curricular nesta área, visando a organizar um conjunto de conteúdos que contemple uma História comum entre os países do MERCOSUL, foi anunciada como medida importante desde o início da criação do Mercosul Educacional.

A construção de uma identidade regional via ensino de História, na promoção e ordenação de uma História em comum, é entendida como uma estratégia política e, sendo assim, é incentivada pelos representantes políticos do MERCOSUL, principalmente por sustentar a ideia de que a formação de um sentimento de pertença a um espaço regional facilitaria a consolidação e a legitimação desse bloco econômico regional.

Em outras palavras, partindo do entendimento de identidade como resultante de articulações discursivas e que, como, tal envolve questões de práticas de significação, de produção cultural e de relações assimétricas de poder, a construção de uma identidade regional, no âmbito do MERCOSUL, associada diretamente ao debate acerca da integração regional, nos remete a um campo discursivo dentro do qual esses sentidos estão sendo disputados.

Em linhas gerais, o que se espera do ensino de História no contexto do MERCOSUL é produzir o sentimento de uma comunidade regional imaginada? Para tal, se colocam em movimento estratégias discursivas que se manifestam por lógicas de equivalência e de diferença que, por meio de processos de condensação e de deslocamento, garantem a dinamicidade do jogo político. A análise dos textos curriculares apontou, como apresentado a seguir, que nesse movimento as tensões entre sentidos de "nacional", "regional" e "local" são reatualizadas e rearticuladas de forma a produzir uma cadeia de equivalência definidora de um sentido de identidade regional latino-americana.

\footnotetext{
${ }^{8}$ Além da disciplina escolar História, a Geografia e o projeto de obrigatoriedade do ensino de Espanhol nas escolas brasileiras e o ensino de Português nas escolas nos demais países hispano-americanos que participam do MERCOSUL estão sendo definidos como instrumentos educacionais mobilizadores na formação da identidade regional pelo MERCOSUL Educacional. Cabe ressaltar também que, no âmbito do Mercosul Educacional, as discussões de reformulação curricular de História e Geografia estão sendo trabalhadas em conjunto. No entanto, esse artigo só se concentrará nas questões específicas à área de História.

9 Pegando emprestado o termo "comunidades políticas imaginadas", cunhado por Benedict Anderson (2008) em seu estudo sobre a formação do nacionalismo no mundo moderno.
} 


\section{A invenção do comum: tensões entre processos de identificação de diferentes escalas territoriais}

Como acervo empírico para a análise neste texto, selecionamos o material da publicação do I e do II Seminário Bienal do Ensino de História e Geografia no contexto do Mercosul $^{10}$, intitulado respectivamente $O$ Ensino de História e Geografia no contexto do Mercosul, organizado por Marilda Marfan, em ocasião do encontro ocorrido em Brasília em 1997, e II Seminário Bienal O Ensino de História e Geografia no contexto do Mercosul, fruto do encontro ocorrido em Montevidéu, em outubro de $1999^{11}$.

Apoiando-se no entendimento de discurso tal como defendido no quadro teórico de Laclau e Mouffe (2004), procuramos explorar nesses textos curriculares as práticas articulatórias produtoras de um sentido de identidade regional, fixado na relação, estabelecida nesse contexto discursivo, com outras marcas de pertencimento territorial que adjetivam processos de identificação como sendo nacional e/ou local.

A potência do termo "discurso", que nos interessa trabalhar, está justamente no fato de ele propor uma forma de enfrentamento das complexas relações entre pensamento e realidade, sujeito e objeto, simbólico e material. Nessas abordagens, nas quais nos inspiramos, o discurso não é percebido como uma operação mental, ideal, em oposição à ação ou à realidade. Ele é relacional e da ordem do material. Uma categoria que une palavras e ações. Uma categoria que não se limita, como afirma Laclau (2005), "aos domínios da fala e da escrita”, e, sim, define-se como "um conjunto de elementos nos quais as relações desempenham um papel constitutivo. Isso significa que estes elementos não preexistem ao complexo relacional, mas se constituem por meio dele" (LACLAU, 2005, p. 86).

Assim, em concordância com Laclau e Mouffe (2004), entendo que os fenômenos sociais e políticos só podem ser interpretados quando inseridos em

\footnotetext{
${ }^{10}$ Esses dois materiais resultaram da reunião de especialistas de ensino de História e Geografia no contexto do Mercosul, ou, melhor, da comunidade epistêmica indicada pelo Setor Educacional do Mercosul, no $3^{\circ}$ e $4^{\circ}$ encontros voltados para discussão da temática em questão. Além de serem os dois materiais a que tive acesso, são os que trazem mais informações sistematizadas a respeito da proposta de um ensino de História e Geografia de perspectiva regional, conforme destacado em alguns textos analisados. É interessante sublinhar que os referidos documentos foram produzidos no final da década de 1990. No mesmo período, foram publicadas as Propostas Curriculares de âmbito nacional para os diferentes níveis da Educação Básica dos países do MERCOSUL, que foram assim denominadas: Contenidos Basicos Comunes para La Educación Basica, na Argentina (1995), Parâmetros Curriculares Nacionais, no Brasil (1997), Programas Del Estudio, no Paraguai (1995), e, no caso do Uruguai, uma proposta de Currículo Experimental foi aprovada a fim de ser aplicada gradativamente para cada etapa da Educação Básica, conhecida como Plan Piloto (1996) (cf. PERES, 2002).

${ }^{11}$ Em termos de organização dos textos produzidos nesse último seminário bienal, há apenas a assinatura de Ana Luiza Machado como Diretora da Oficina Regional de Educação da UNESCO para a América Latina e Caribe, na parte de apresentação do documento, que foi publicado com o apoio da UNESCO.
} 
uma cadeia de significação discursiva, sem a qual nenhum sentido pré-existencial pode ser acessado. Esses autores assumem que as cadeias de significação são resultantes de práticas articulatórias que operam com duas lógicas diferentes mas complementares: a lógica da equivalência e a lógica da diferença. São essas lógicas que garantem a produção dos diferentes sentidos sempre em disputa em determinada formação discursiva. Afinal, como afirma Laclau, "algo é o que é somente por meio de suas relações diferenciais com algo diferente" (LACLAU, 2005, p. 92).

As lógicas da equivalência e da diferença são responsáveis pela fixação de sentidos, que é sempre parcial, devido "à abertura do social", argumentando, assim, que as formações discursivas consistem em elementos relacionados que podem, em certos contextos, ser significados como uma totalidade (HOWARTH, 2005).

Esses elementos que se encontram envolvidos em uma mesma cadeia de equivalência são diferenças articuladas, o que faz que tenham, ao mesmo tempo, suas demandas particulares ainda presentes, mas que, em relação à articulação que os envolve, cancelam suas diferenças nesse contexto discursivo particular.

Essa postura epistêmica abre outras possibilidades de enfrentamento à questão da definição das coisas desse mundo, como a "identidade regional latino-americana". Trata-se de pensarmos em um significante capaz de exercer uma função discursiva do lugar da fronteira, do limite radical, que permita nomear esse fechamento. Isso faz que alguns significantes do discurso sejam privilegiados no fechamento da cadeia de significação.

Como afirma Macedo (2006) ao se referir aos processos de identificação/ significação:

Os fluxos são estancados por articulações hegemônicas provisórias, que fecham o campo discursivo que se constrói em torno de significantes instáveis. Assim, poderíamos definir a identidade como uma estabilização temporária produzida em lutas hegemônicas, por um corte de fluxos de sentidos (MACEDO, 2006, p. 33).

Assim, reconhecer no jogo político a condição de fechamento do social implica valorizar, nas nossas análises, as categorias fronteira e limite como territórios de lutas políticas, isto é, de lutas por significação. A teoria laclauniana traz uma contribuição substantiva para pensar sobre esse estancamento. Para este autor, o processo de significação implica pensar fechamentos contingenciais, provisórios e precários. É, pois, a função discursiva da noção de "limite" do sistema de diferenças que permite essa operação teórica da significação. Nas palavras de Laclau (2005, p. 71, tradução livre): 
De tal modo, encontramo-nos na situação paradoxal de que aquilo que constitui a condição de possibilidade de um sistema significativo, seus limites, é também aquilo que constitui sua condição de impossibilidade, um bloqueio na expansão contínua do processo de significação.

Isso nos permite olhar para o espaço-tempo de fronteira chamado currículo de História produzido no contexto do MERCOSUL como um sistema incompleto cujos limites estão sob forte pressão em nosso presente. Afinal, como alerta Hall (2000, p. 109):

É precisamente porque as identidades são construídas dentro e não fora do discurso que nós precisamos compreendê-las como produzidas em locais históricos e institucionais específicos, no interior de formações e práticas discursivas específicas, por estratégias e iniciativas específicas. Além disso, elas emergem no interior do jogo de modalidades específicas de poder e são, assim, mais o produto da marcação da diferença e da exclusão do que o signo de uma unidade idêntica, naturalmente constituída, de uma "identidade" em seu significado tradicional - isto é, uma mesmidade que tudo inclui, uma identidade sem costuras, inteiriça, sem diferenciação interna.

Interessa-nos compreender a prática articulatória resultante das lógicas de equivalência e de diferença acionadas no contexto do MERCOSUL, que procura hegemonizar um sentido de identidade regional nesses documentos curriculares de História produzidos no âmbito do SEM. Dito de outra forma, propomos analisar os processos simultâneos de deslocamento - de sentidos de diferentes significantes que participam da cadeia de equivalência - e de condensação em torno de um significante que assume a função discursiva do que, na teoria do discurso, é chamado de "ponto nodal". Que termos são utilizados no documento para nomear esse tipo de marca identitária? Que significantes são mobilizados para formar a cadeia de equivalência definidora de "identidade regional"? Que significantes são excluídos dessa mesma cadeia, possibilitando seu fechamento provisório? Qual é a função discursiva nessa prática articulatória de significantes como identidade nacional e/ou identidades locais? Que significante emerge nesses documentos com força suficiente para assumir a função discursiva de ponto nodal? Como o discurso histórico é mobilizado em meio a essas lógicas de articulação?

Uma primeira observação a ser feita diz respeito ao fato de a expressão "identidade regional" não ser um significante utilizado com frequência nos documentos analisados. No entanto, a demanda de formação de uma "identidade regional latino-americana" por meio do ensino de História está presente nos documentos analisados, traduzindo, em nosso entendimento, a inserção dessa proposta curricular no atual processo de globalização, bem como uma resposta política possível aos efeitos desse processo em termos das relações de poder 
no cenário político internacional. Não é aleatório o fato de as argumentações a favor de um sentimento de pertença ao espaço sul-americano, definido como espaço regional do MERCOSUL, estarem diretamente relacionadas à defesa da ideia de integração econômica, como deixam transparecer passagens como as que seguem:

De fato, a integração, como categoria de análise histórica, não parece como prioridade na confrontação e no desenvolvimento de nossas nações, ainda que hoje seja percebida como uma necessidade para os países da região num contexto de acirrada concorrência global. (Heraldo Munoz. O Ensino de História e Geografia no contexto do Mercosul, 1997, p. 29; 31-35, grifo nosso) ${ }^{12}$.

Espaço que transcende a esfera do mercado e dos interesses econômicos e que, no contexto do Mercosul, deve ser o lugar em que toda sociedade pode interagir em busca de sua identidade. [...] devemos estar desencadeando um processo que deve atingir todos os países do Mercosul, e que a transmissão aos alunos dessa nova percepção da realidade em que vivemos é o ponto de partida fundamental para a formação de uma identidade regional. (Iara Prado. O Ensino de História e Geografia no contexto do Mercosul, 1997, p. 7-9, grifo nosso).

No primeiro fragmento, é possível evidenciar o processo de universalização de demandas de grupos particulares associados a interesses econômicos. A generalização da integração regional como interesse de todos induz uma suposta aprovação unânime desse acordo econômico pela sociedade civil. A criação do MERCOSUL está assentada em interesses econômicos, e o papel do ensino de História nesse contexto mistura-se a tais interesses, com o intuito de fortalecer o argumento que considera a integração regional "uma necessidade para os países da região num contexto de acirrada concorrência global”.

Já no segundo fragmento acima, a utilização da expressão "busca de sua identidade" tende a operar com uma concepção de identidade essencialista pressupondo a existência de uma identidade [regional], que precisa ser encontrada, indicando que ela está em algum lugar, adormecida, ocultada, possivelmente pelas experiências históricas anteriores dos países envolvidos. Ao passo que a afirmação de que o MERCOSUL corresponde a uma "nova realidade social" - integrada regionalmente -, que exige, portanto, a "formação de uma identidade regional", que tem como ponto central a construção de algo que consolide simbolicamente os propósitos do regionalismo no contexto da globalização. $\mathrm{Na}$ luta pela consolidação dos interesses que giram em torno de uma integração regional, a identidade regional ora se apresenta como algo a priori, ora como elemento a se construir. Essas ambivalências são pistas para a compreensão de como o sentido de identidade regional tem sido mobilizado no interior das discussões da proposta de reformu-

\footnotetext{
${ }^{12}$ A transcrição de trechos dos documentos analisados, contidos na obra de Marfan (1997), será identificada pelo nome do autor do texto, seguido do título do documento referente, ano da publicação e página.
} 
lação curricular de História, indicando igualmente os conflitos que permeiam a definição de qual deve ser um currículo de História no contexto do MERCOSUL. Um currículo que ora permita construir uma "nova identidade", ora desvelar uma "identidade apenas adormecida". Um exemplo dessa perspectiva de "desvelamento" é a reatualização de discursos de outros momentos históricos, que apresentam marcas discursivas semelhantes, como, por exemplo, o que ficou conhecido como bolivarismo ${ }^{13}$. A referência, por exemplo, ao ideal de uma "América Latina unida" é apresentada mais de uma vez nos documentos. Na parte final do artigo apresentado no I Seminário Bienal, o texto assume uma espécie de "campanha" para um ensino de História e Geografia aliado à consolidação do MERCOSUL.

A pertinência e a necessidade, defendidas nesses textos, de "buscar" essa identidade regional se sustentam discursivamente por meio de processos de deslocamento metonímico que colocam em uma mesma cadeia de equivalência significantes como "consciência histórica", "consciência cidadã" e "integração econômica". Como deixam entrever os trechos trazidos como exemplos, esses termos participam da atribuição de sentidos de identidade regional por meio do Ensino de História no âmbito do Mercosul Educacional, evidenciando a presença de hibridizações entre discursos produzidos em diferentes áreas das ciências sociais, como História, Ciências Políticas ou Economia. Os trechos abaixo sintetizam bem esse movimento da lógica de equivalência.

[...] com o desenvolvimento do Mercosul Educacional, peça-chave no processo de integração regional, preconizando a necessidade de formação de uma consciência cidadã que transcenda a nacionalidade e que crie em nossas crianças e adolescentes o sentimento de cidadãos que constroem seu espaço - físico, econômico e cultural - dentro de um mundo globalizado e multipolar: o espaço do Mercosul. [...] todos aqueles ligados à produção, à reprodução, ao consumo e à transmissão do conhecimento, paladinos da consolidação do Mercosul, que acreditam e se esforçam pelo engrandecimento da América Latina, pelos nossos lacos de irmandade e pelo desenvolvimento de nossos povos. (Paulo Renato de Souza. O Ensino de História e Geografia no contexto do Mercosul, 1997, p. 5, grifo nosso).

[...] tentar fazer que a História e a Geografia sejam disciplinas formadoras de uma consciência cidadã que transcenda a própria nação, de forma que crianças e adolescentes se sintam cidadãos do mundo e cidadãos de um espaço que se consolida: o Mercosul. (Iara Prado. O Ensino de História e Geografia no contexto do Mercosul, 1997, p. 8, grifo nosso).

A articulação entre função atribuída ao ensino de História e os preceitos da globalização econômica está colocada de forma explícita, reafirmando o papel determinante dessa disciplina escolar para a sustentação do argumento de que

\footnotetext{
${ }^{13}$ Relaciona-se ao pensamento de Simón Bolívar (1783-1830) quanto à proposta de uma integração latino-americana.
} 
uma "integração econômica, educativa, cultural e social de nossos países torna-se imprescindível para uma sobrevivência melhor em um mundo globalizado e multipolar" (PRADO, Iara. O Ensino de História e Geografia no contexto do Mercosul, 1997, p. 7).

Assim, fundamenta-se a defesa de um ensino de História de enfoque regional como base da consolidação do MERCOSUL enquanto bloco econômico regional, atuando em várias esferas da sociedade, como a Educação. Os termos "integração regional" e "identidade regional" se confundem, sendo empregados para reforçar a afirmação de um ensino de História voltado para o enfoque regional, dando margem à ambivalência de sentidos.

Essas ambivalências de sentidos fazem parte do jogo de linguagem dos processos de significação/identificação e reforçam ainda mais a complexidade de se organizar um currículo de História orientado pela invenção de uma identidade regional a fim de atender a interesses econômicos, em meio a discursos historiográficos que tendem a apresentar resistência em fortalecer ou reconhecer os laços culturais possíveis de ser referenciados por essa marca identitária.

Do mesmo modo, a expressão "consciência cidadã" é significada de forma a fixar a ideia de uma identidade regional, associada às determinações do mundo globalizado, no qual se encontra o MERCOSUL na condição de bloco econômico, visando a sua consolidação no cenário mundial pela integração regional entre os países integrantes. O sentido de identidade regional atrelado ao ensino de História é, portanto, fixado por fluxos de sentidos de cidadania muito mais identificados com as questões econômicas do que com as questões culturais, apesar da questão cultural aparecer como pano de fundo na definição dos planos educacionais do SEM, servindo como alegação da construção de uma identidade regional por meio, por exemplo, da defesa do fortalecimento dos laços culturais entre os países do MERCOSUL.

Nas estratégias discursivas mobilizadas nos documentos analisados, esse forjamento de uma identidade latino-americana pela articulação de diferentes significantes - "consciência cidadã", "integração regional" -, por meio da lógica de equivalência, pressupõe a exclusão de outros significantes dessa mesma cadeia de significação. Nesse movimento, é interessante sublinhar como o discurso da História e/ou da historiografia é mobilizado ora pela lógica de equivalência, ora pela lógica de diferença - esta última é responsável pela produção de um antagonismo que permite estabelecer uma fronteira entre o que "é" e o que "não é" "identidade regional" nesses documentos. O trecho a seguir permite acompanhar esse movimento pendular. 
[...] comecemos por refletir em conjunto para remodelar o ensino da História e da Geografia. Temos que ensinar de uma outra maneira, porque as circunstâncias atuais são outras, bem como a finalidade do ensino desses saberes também é outra. Já não se trata apenas de formar os cidadãos nacionais de cada Estado, trata-se agora de formar o cidadão inserido na globalização, que seja capaz de manusear e integrar simultaneamente diversas dimensões espaciais e temporais; um homem que possua competência para movimentar-se, conhecer e participar ao mesmo tempo, na sua localidade, no seu país e na sua região, e que tenha a suficiente consciência sobre o tempo social e individual para poder captar as diferentes oportunidades que se lhe apresentam em cada âmbito. Aproveitamos a presença de geógrafos e historiadores que já estão trabalhando com novos horizontes, gerando perguntas e produzindo respostas, pensando e sonhando, mais uma vez, com uma América Latina unida (Adela Pereyra. O Ensino de História e Geografia no contexto do Mercosul, 1997, p. 24, grifo nosso).

Uma primeira estratégia consiste em apontar a inadequação de sentidos de "cidadania" e de "identidade nacional" até então hegemônicos - "Já não se trata apenas de formar os cidadãos nacionais de cada Estado" - frente às demandas de nosso presente. Em seguida, "resgatam" e positivam certo sentimento de pertencimento ao espaço latino-americano, acionando um "sonho antigo da América latina unida”, buscando assim dar maior legitimação a esse intento.

A tensão entre identidade regional e identidade nacional envolve diretamente a questão da remodelagem da função do ensino de História, relacionada aos processos de identificação que mobilizam diferentes "escalas territoriais" de pertencimento. Isso implica para o ensino de História contribuir na formação de um cidadão que se reconheça ao mesmo tempo como cidadão em sua localidade/região (interna ao Estado Nacional em que vive), cidadão nacional e cidadão regional (para além do espaço nacional). Essas mudanças forçam uma redefinição da articulação entre ensino de História e produção de identidade/diferença. Como equacionar a construção de outras identidades que têm como referência escalas identitárias territoriais que não fiquem limitadas ao espaço nacional sem, no entanto, abrir mão dessa última? Ou ainda que sentido de nacional fixar na negociação pela fixação discursiva de identidade regional?

Percebe-se que o apelo a um sentimento de pertencimento nacional é problematizado, mas não de todo apagado. Defendemos que a marca identitária assume papel central nesse jogo de linguagem, acionando e hibridizando perspectivas historiográficas distintas ora sendo mantidas como mais um momento da cadeia de equivalência definidora de identidade regional, ora exercendo o papel de exterior constitutivo dessa mesma cadeia, permitindo assim a fixação provisória desse significante.

Desse modo, em algumas passagens, certo sentido de identidade nacional, pautado em perspectivas historiográficas tradicionais, é problematizado sem 
portanto colocar em questão o sentimento de pertencimento a uma nação. Ao contrário, a identidade regional é entendida como resultante de processos articulatórios entre as diferentes identidades nacionais.

Por outra parte, observa-se uma primazia da História nacional, com referenciais marginais aos países vizinhos da região. Mas nem sequer as Histórias estritamente nacionais podem ser adequadamente explicadas sem transcender as fronteiras oficiais. Existe, portanto, uma História que deve ser submetida a revisão com critério científico e crítico. Tanto uma História particular dos países como a História comum da região precisam ser valorizadas. A integração não implica ameaças às identidades nacionais. Unidade na diversidade é um objetivo razoável neste sentido. (Heraldo Munoz. O Ensino de História e Geografia no contexto do Mercosul, 1997, p. 29; 31-35, grifos nossos).

Finalmente, este encontro patrocinado pelo Ministério da Educação é um importante passo na direção da integração das nossas Histórias nacionais, para reencontrarmo-nos com uma História comum esquecida e para relatar a nova História que os nossos povos hoje constroem e anseiam tornar cada vez mais uma firme realidade. (Heraldo Munoz. O Ensino de História e Geografia no contexto do Mercosul, 1997, p. 29; 31-35, grifos nossos).

Em outros trechos dos documentos, percebe-se que, além da ampliação de um sentido de consciência cidadã, ou do apelo ao resgate de um sentimento de pertencimento perdido, também foram incorporadas nos encontros dos seminários pela comunidade epistêmica ${ }^{14}$ envolvida no desenvolvimento de uma proposta curricular de História comum as críticas a uma historiografia pautada em um nacionalismo percebido como verdadeiro empecilho à construção de uma identidade regional supranacional. Neste caso, o sentimento de identidade nacional está diretamente articulado às perspectivas do nacionalismo historiográfico de enfoque bélico-político, que tendem a ser problematizadas e combatidas nos documentos analisados, na medida em que são identificadas como aspectos prejudiciais à construção de uma identidade regional pelo ensino de História no contexto do MERCOSUL.

A América Latina é uma região atomizada, dividida, desintegrada, e sua historiografia e geografia refletem essa enorme carência de identidade comum e de um projeto político unitário. Predominam na nossa região as histórias nacionais; cada país visualiza-se a si mesmo como uma ilha, ignorando seus vizinhos ou, em alguns casos, onde houve conflitos fronteiriços, até satanizando-os.

\footnotetext{
${ }^{14}$ De acordo com Peter Haas (1992, apud DIAS; LÓPEZ, 2006, p. 57), a definição de comunidades epistêmicas diz respeito a "uma rede de profissionais com especialistas e competências reconhecidas em um domínio particular e com autoridade legitimada em termos de conhecimentos politicamente relevantes associados àquele domínio ou área de conhecimento".
} 
[...] Certamente não podemos narrar nossa História sem fazer referência às guerras e aos conflitos fronteiriços. Mas há um excesso de ênfase nos conflitos na historiografia das relações entre os Estados latino-americanos (Heraldo Munoz. O ensino de História e Geografia no contexto do Mercosul, 1997, p. 29; 31-35)

Um dos obstáculos mais formidáveis para o sucesso da integração regional e, de maneira especial, para o processo integrador do Mercosul é a herança do Tratado de Tordesilhas de 1494, assinado entre Portugal e Espanha, que traçou os limites coloniais das duas potências nas Américas. [...]. Precisamos agora vencer a herança ruim de Tordesilhas. O Mercosul é um grande avanço nesse sentido. Não só o comércio entre os quatro parceiros do bloco [...], mas as tradicionais hipóteses de conflitos entre Argentina e o Brasil mudaram.

[...] Nesse sentido, e voltando ao tema da separação entre os latino-americanos de origem portuguesa e espanhola, a realização de sucessivas cúpulas ibero-americanas de Chefes de Estado e de Governo tem ajudado a superar a sindrome de Tordesilhas, fortalecendo a identidade comum e a integração entre os membros da denominada "Comunidade Ibero-americana". [...] (Heraldo Munoz. O Ensino de História e Geografia no contexto do Mercosul, 1997, p. 29; 31-35, grifos nossos).

Esses fragmentos permitem exemplificar como vem sendo construída a argumentação em prol da fixação de um sentido de identidade regional latino-americana na relação com os sentidos de identidade nacional nesse contexto discursivo específico. Oscilando entre a ênfase no papel nocivo da História nacional dos países do MERCOSUL - na medida em que, nos discursos nacionalistas historiográficos, se tenderia a não estabelecer aproximações entre as respectivas narrativas nacionais, colocando em evidência os conflitos territoriais ocorridos entre alguns dos países do MERCOSUL - e a mobilização de tradições inventadas, os textos analisados reatualizam em permanência sentidos do significante "identidade", que assume o lugar de significante flutuante, metamorfoseando seus significados para dar conta das diferentes demandas que tentam se articular em torno do termo.

Desse modo, a incorporação de expressões como "consciência cidadã", "integração regional”, "integração econômica” em uma mesma cadeia de equivalências para a definição de identidade regional tende mais a fortalecer os interesses econômicos em jogo no MERCOSUL do que a buscar deslocar as fronteiras hegemônicas de definições estabilizadas, como as de identidade nacional, muitas vezes sentadas na legitimação da integração regional como proposta política e econômica.

Por fim, uma hipótese que começou a se delinear a partir dessa análise diz respeito à incapacidade do significante "identidade regional" assumir nessas articulações o lugar de ponto nodal apto a articular as demandas formuladas no 
contexto do MERCOSUL. A identidade regional supranacional, uma demanda do MERCOSUL, acaba não sendo considerada uma nova marca identitária suficientemente forte para subverter a hierarquia do pertencimento nacional, que, de certa forma, continua agregando a ideia do universal. Essa persistência da marca identitária nacional pode ser explicada pela ausência nesses documentos das contribuições de perspectivas historiográficas que incorporam demandas de diferença que permitem outras articulações entre universal e particular.

Desde 1992, o Setor Educacional do Mercosul vem trabalhando com o objetivo de aprovar uma proposta curricular de História de enfoque regional, que contribua na construção de uma identidade regional e na legitimação do MERCOSUL. Até agora, já faz dezenove anos que esse projeto está em desenvolvimento. A demora na oficialização pode ser um forte indicativo da dificuldade que se tem de formular um projeto identitário, tendo como suporte a reformulação curricular de História, que, por sua vez, envolve países com diferentes demandas, apesar de estarem integrados a um espaço regional comum.

Para finalizar, cumpre lembrar que, no quadro teórico assumido neste estudo, não se trata de defender um sentido mais verdadeiro ou correto de identidade regional ou nacional. O jogo politico está sempre aberto a novas rearticulações. O que importa é nossa possibilidade de "identificar as regras e convenções específicas que estruturam a produção de significados em contextos históricos particulares" (HOWARTH, 2000, p.128) para nos posicionarmos como professores e pesquisadores da área nessa disputa. Esse texto foi uma tentativa de explorar essa possibilidade.

\section{Referências}

ANDERSON, B. Comunidades Imaginadas: reflexões sobre a origem e a difusão do nacionalismo. Tradução de Denise Bottman. São Paulo: Companhia das Letras, 2008.

BALL, S. J. Politics and policy making in education: explorations in policy sociology. New York: Routledge, 1990.

BALL, S. J. What is policy?: Texts, trajectories and toolboxes. Discourse, London, v. 13, n. 2, p. 10-17, 1993.

BALL, S. J. Education Reform: a critical and post-structural approach. Buckingham: Open University Press, 1994.

BALL, S. J. Cidadania global, consumo e política educacional. In: SILVA, L. H. A escola cidadã no contexto da globalização. Petrópolis: Vozes, 1998. p. 121-137.

BALL, S. J. Diretrizes políticas globais e relações políticas locais em educação. Currículo sem Fronteiras, Porto Alegre, v. 1, n. 2, p. XXVII-XLIII, 2001.

BALL, S. J. Performatividade, privatização e o pós-Estado do bem-estar. Educação e Sociedade, Campinas, v. 25, n. 89, p. 1105-1126, set./dez. 2004. 
BHABHA, H. O local da cultura. Belo Horizonte: Editora da UFMG, 1998.

BRASIL. MERCOSUR/RME/Acta $\mathbf{n}^{0}$ 02/92. Acta de la reunión de ministros de educación de los países signatarios del Tratado del Mercado Común del SUR-MERCOSUR. Brasília, 27 nov. 1992.

BRASIL. Ministério da Educação. Parâmetros Curriculares Nacionais (5 a $8^{\mathrm{a}}$ séries): História. Brasília: MEC/SEF, 1998.

CUNHA, C. da. O MERCOSUL e a Educação Básica. Em Aberto, Brasília, v. 5, n. 68, p. 9-15, out./dez. 1995.

DIAS, R.; LÓPEZ, S. B. Conhecimento, interesse e poder na produção de políticas curriculares. Currículo sem Fronteiras, Porto Alegre, v. 6, n. 2, p. 53-66, 2006.

GABRIEL, C. T. A identidade (nacional) na berlinda: uma forma possível de entrar no debate em torno da educação intercultural. In: CANDAU, V. (Org.). Cultura(s) e Educação: entre o crítico e o pós-crítico. Rio de Janeiro: DP\&A, 2005. p. 39-72.

GABRIEL, C. T. Conhecimento escolar, cultura e poder: desafios para o campo do currículo em "tempos pós”. In: MOREIRA, A. F.; CANDAU, V. M. (Orgs.). Multiculturalismo: diferenças culturais e práticas pedagógicas. Petrópolis: Vozes, 2008. p. 212-245.

GARCÍA CANCLINI, N. Culturas híbridas. São Paulo: Edusp, 1998.

GARCÍA CANCLINI, N. Culturas híbridas: estratégias para entrar e sair da modernidade. 4. ed. São Paulo: Edusp, 2003.

GOODSON, I. Currículo: teoria e história. Petrópolis: Vozes, 1995.

HALL, S. A centralidade da cultura: notas sobre as revoluções do nosso tempo. Educação e Realidade, Porto Alegre, v. 22, n. 2, p. 15-46, jul./dez. 1997.

HALL, S. Quem precisa de identidade?. In: SILVA, T. T. (org.). Identidade e diferença: a perspectiva dos estudos culturais. Petrópolis: Vozes, 2000. p. 103-133.

HALL, S. A identidade cultural na pós-modernidade. Tradução de Tomaz Tadeu da Silva e Guacira Lopes Louro. 10. ed. Rio de Janeiro: DP\&A, 2005.

HOBSBAWM, E.; RANGER, T. (Orgs.). A invenção das tradições. Rio de Janeiro: Paz e Terra, 1984.

HOWARTH, D. Applying discourse theory: the method of articulation. In: HOWARTH, D.; TORFING, J. Discourse theory in European politics. New York: Palgrave Macmillan, 2005. p. 316-349.

HOWARTH, D. Discourse. Buckingham/Philadephia: Open University Press, 2000.

II SEMINÁRIO BIENAL. O ensino de História e Geografia no contexto do Mercosul. Santiago: UNESCO, 2001.

LACLAU, E. Emancipación y diferencia. Buenos Aires: Difel, 1996.

LACLAU, E. Populismo, o que existe num substantivo?. Margens/Márgenes, Belo Horizonte/Buenos Aires, n. 3, p. 4-15, jul. 2003.

LACLAU, E. La razón populista. Buenos Aires: Fondo de Cultura Econômica, 2005. 
LACLAU, E.; MOUFFE, C. Hegemonía y estrategia socialista: Hacia una radicalización de la democracia. Buenos Aires: Fondo de Cultura Económica de Argentina, 2004.

LOPES, A. C. Políticas Curriculares: continuidade ou mudança de rumos. Revista Brasileira de Educação, Rio de Janeiro, n. 26, p. 109-118, maio/ago. 2004.

LOPES, A. C. Discursos nas políticas de currículo. Currículo sem Fronteiras, Porto Alegre, v. 6, n. 2, p. 33-52, 2006.

MACEDO, E. Currículo e hibridismo: para politizar o currículo como cultura. Educação em Foco, Juiz de Fora, v. 8, n. 1-2, p. 13-30, mar. 2003/fev. 2004.

MACEDO, E. Currículo como espaço-tempo de fronteira cultural. Revista Brasileira de Educação, Rio de Janeiro, v. 11, n. 32, p. 285-296, maio/ago. 2006.

MAINARDES, J. Abordagem do ciclo de políticas: uma contribuição para a análise de políticas educacionais. Educação e Sociedade, Campinas, v. 27, n. 94, p. 47-69, jan./abr. 2006.

MARCHART, O. El pensamento político posfundacional: La diferencia política en Nancy, Lefort, Badiou y Laclau. Buenos Aires: Fondo de Cultura Económica, 2009.

MARFAN, M. A. (Org.). O ensino de História e Geografia no contexto do Mercosul. Brasília: MEC/SEF, 1997.

PERES, S. Ensino de História e identidade no Mercosul. In: CORSETTI, B. Ensino de História: formação de professores e cotidiano escolar. Porto Alegre: EST, 2002. p. 143-151.

POLETO, D. W. Integração latino-americana e educação: o plano trienal de educação para o Mercosul. Estudos Ibero-Americanos, Porto Alegre, v. XXI, n. 2, p. 139-144, dez. 1995.

TRATADO DE ASSUNÇÃO. Tratado para a constituição de um mercado comum entre a República Argentina, a República Federativa do Brasil, a República do Paraguai e a República do Uruguai. 1991.

Recebido em 21/02/2013

Versão final recebida em 14/06/2013

Aceito em 17/06/2013 